\title{
The use of participant-observation protocol in an industrial engineering research
}

\author{
Renato da Silveira e Silva ${ }^{a}$, Laerte Idal Sznelwar ${ }^{a *}$ and Victor D'Afonseca e Silva ${ }^{a}$ \\ ${ }^{a}$ Production Engineering Department ${ }^{-}$University of São Paulo Av. Prof. Almeida Prado, Travessa 2, nr. 128 - \\ São Paulo/SP - Brazil 05508-070
}

\begin{abstract}
Based on literature, this article aims to present the "participant-observation" research protocol, and its practical application in the industrial engineering field, more specifically within the area of design development, and in the case shown by this article, of interiors' design. The main target is to identify the concept of the method, i.e., from its characteristics to structure a general sense about the subject, so that the protocol can be used in different areas of knowledge, especially those ones which are committed with the scientific research involving the expertise from researchers, and subjective feelings and opinions of the users of an engineering product, and how this knowledge can be benefic for product design, contributing since the earliest stage of design.
\end{abstract}

Keywords: participant observation, research scientific, product design, product engineering.

\section{Introduction}

Bouchard $^{1}$ [1] (1976) says that the term "participant-observation" was apparently created by Lindernan [2] (1924), and later, Hader and Lindeman [3] (1933, p. 148) give the following definition and rationale of the method:

The participant-observation is based on the theory that an interpretation of an event can only be approximately correct when dealing with a set of two points of view, the external and internal. Thus, the vision of the person who has been a participant in the event, whose desires and interests have been, somehow, monitored, and the vision of the person who was not a participant but an observer or analyst, merge into a complete synthesis.

In other words, participant-observation is when the perspective of those who observe an ongoing action in order to study it and the perspective of who performs the action fuse, i.e., the researcher is the same as performing the action and gets the result of its action. Bouchard [1] (p. 385) presents three advantages to this method: the first is that it focuses the attention of the researcher on the behavior of individuals and not just in an interview or behavior, the second is that it forces the researcher to observe

\footnotetext{
* Corresponding Author. Email: laertesz@usp.br

${ }^{1}$ Professor of Minnesota University - EUA
}

all the individuals, organizations and environments in an integrated manner, and the third, and possibly the best reason for using this method is that it puts the researcher inside the context of the research.

Most of the texts already published about this concept are directly related to area of knowledge that involves the human sciences such as psychology and anthropology. In this article it will be conceptualized the theory about the protocol; the debate of the assertiveness on this research format considering the humanistic approach from most of the bibliographic material found - aiming to relate the concepts to the technical area of engineering and design. Since this protocol provides not a simple observation but a living experience, it ought to be strongly useful for a designer when developing projects, especially interiors' spaces.

\section{Theoretical conceptualization of the participant-observation protocol}

Participant-observation is a qualitative method with roots in traditional ethnographic research, whose goal is to help researchers understand the perspectives achieved by populations of study. Qualitative research is done through isolated 
observation or by concerted action of observation and participation in different degrees in the daily activities of the study. Participant-observation always takes place in community settings, in locations where it is believed to have some relevance to the research questions. The method is characteristic because the researcher approaches to environment of the participants, instead of the participants come to the researcher. In general, the researcher engaged in participant-observation tries to learn how is the life as an "insider", while remaining an "outsider", inevitably. (Mack et al. [4], 2005, p. 13).

Cicourel $^{2}$ [5] (apud Haguette, 1982, p. 62 apud Costa [6], without date), says that participantobservation "is a process in which the presence of the observer is maintained in order to the scientific research purposes, focusing on the behavior and relationships in certain situations," and it is "indicated to capture the hidden meaning of human action, because part of the belief in free will, which strongly opposes the perception of social action only as a result of structural factors".

The participant-observation to Glancy [7] (1986) is a means to investigate a social setting from the perspective of symbolic interactionism. Theoretically, the objective is that the researcher should be able to understand the definition of the observed object as a participant that both is the sense of reality and is simultaneously altered by experience with the event you want to understand. (Mead [8], 1934). The possibility of allowing the observer and the observed become one, does the participant-observation as the central strategy of symbolic interactionism. The utilization of this method is offered as an example of an approach to provide holistic view of phenomena and, in addition, participant-observation is one way to get a cognitive view of the world through the eyes of the participant.

According to Schmid [9] (apud Foster [10], 2006), "participant-observation is a species of type of action research, which imposes heavy burden on the researcher, requires 2-3 years of permanence in the project, even in an abridged version, and, the researcher is the instrument of observation.

Garson $^{3}$ [11] (2008) affirms that participantobservation is a simple technique: by immersing

\footnotetext{
${ }^{2}$ Source: http://mundoacademico.unifap.br/professor/23/view= verarquivo \&co $=152$. Original bibliography is not clearly mentioned.

${ }^{3}$ Doctor Professor of Public Business and International. CHASS

College of Humanities and Social Sciences, North Carolina State University.
}

himself in the subject under study, usually during a long period of time, the researcher seeks to obtain an understanding, perhaps more deeply than could be obtained through a questionnaire. Arguments in favor of this method include reliance of firsthand information, of high validity data and confidence in relatively simple and inexpensive methods. The disadvantage of participant-observation as a technique of data collection is greater threat to the objectivity of the researcher because the data collection non-systematic, the subjective measure and the possible effects of the observer since observation can distort the observed. Participantobservation is particularly suitable for studies of interpersonal group processes. Summing-up, the researcher, during the observation, participates actively with the observed phenomenon. Thus, observer and observed stay in the same level where are experienced the same situations.

About the disadvantages of the method, Martins ${ }^{4}$ [12] (2004) ponders that the qualitative researches, and among them the participant-observation, can compromise the criteria and results, considering the relationship between the researcher and the researched object, because there would be a risk of lack of neutrality and objectivity of scientific knowledge. The author affirms in her article that "it is a method, mainly used by anthropology, but also in sociology, that is what raises more questions about that approach" (pp. 294).

The website www.sociology.org.uk [13] works the concept of participant-observation as being "some time called as a form of subjective sociology, not because the researcher intents to impose beliefs on the interviewee - that would just produce bad data - but because the objective is to understand the social world, from the point of view of the subject." Still according to this website, participantobservation is a method in which the researcher seeks "to obtain the knowledge", though the dip in the subject studied, i.e., the researcher must put himself "in the skin" of the studied people, in an attempt to experience events with objectivity that is "the ability to keep detached, distant or in person separate from" the researched object, with empathize that is "the ability to take the part of the other" (Mead [8], 1934). Therefore, we have to consider that participant-observation is essentially an interpretive methodology that seeks to

\footnotetext{
${ }^{4}$ Graduated in Social Sciences (1963), Master in Sociology (1974) and Ph.D. in Sociology (1986) at University of São Paulo. http://lattes.cnpq.br/2159479521561496.
} 
understand the motives and a meaning from the point of view of those involved in the study object, and generates quality and depth of information. It differs from other qualitative techniques of data collection since the research-scientist is who formulates hypotheses, tests them and finally producing a report equivalent to the output data from a questionnaire, in case it were applied to a member of the sampling population not linked to the scientific group; not requires any specific instrument for orientating the observation (questionnaire or interview script) since the observer will perform the action under study focused on encouraging comments about the items for which response is sought; requires that the observer be accurately enough to identify what is relevant to be observed (non-verbal communication as facial expressions, gestures and postures, and verbal, as jokes, anecdotes on the subject, and comments).

According to the Guidelines for Ethical Conduct in Participant-Observation [14], when the researches participate in the process as a participant-observer, they must be as aware as possible, so that the researcher who practice participant-observation has not only one role - of a researcher - but running a variety of statutes and roles; to be especially sensitive to differences in age, sex, weight, height, social class, health and culture; be aware of possible confrontations; be aware of the development of roles and of the relationships throughout the time that may arise as a result.

Alves-Mazzotti and Gewandsznajder [15] (2002, apud Ferreira and Mousquer [16]) describe that "the participant-observer characteristics are similar to the good interviewer, that is, a good listening skills and empathy, have a good capacity of adaptation to unexpected situations, become acquainted with the studied situation and have to have ability to formulate many questions."

As a consequence, the subjectivism concentrated on a person who experiences it and provides the analysis not registered as a method failure, but as an understanding of that tool will generate data that must receive treatment, considering the detailed descriptions of the researcher who has been experienced the proposed situation.

\section{Connection between the protocol and engineering}

From the sociology standpoint, the participantobserver studies people inside the natural environment, getting a deep vision of the behavior which does not arise simply from close and detailed observation, but also from the own researcher experience in the group being studied - a technique that provides insights in first hand asking why people behave that way, that is, which motivations and intentions on desired actions, and assumptions that permeate such acts. In addition, participantobservation does not affect issues and events (in the form a questionnaire can, for instance) and, for these reasons, it is arguable that this method provides data that have a high level of validity (sociology.org.uk) [13].

When we seek to make the proper correlation of the methodology to the engineering area, the natural way would be to search for engineering the boundary between design/product and the person, since the method in question is centered in understanding of the person who was immersed in a particular context. Silva ${ }^{5}$ [17] (1998) in his PhD thesis, affirm that the human being as user of engineering products, must have legitimized the perceptions, sensations and feelings in a more comprehensive and integrated form - so that the science of engineering will be increased and become narrow the relationship between the humanities and social sciences.

Through participant-observation methodology, engineering may be able to understand people's behavior, as well as the use motivations and use form of a product or service. Especially when it depends excessively on subjective evaluations, such as comfort, beauty and appearance, "what seems good and nice"; analyzes the interface between the product (object built by the engineer on which to perform the action) and humans (observed) by the participant-observation method is enriching. Since the data collection about the subjective perceptions would be extremely complicated, if the same person is observed and researcher (participant-observer),

\footnotetext{
${ }^{5}$ D.J. Silva. Degree in civil engineering (1976), Federal University of Santa Catarina, Brazil; expertise in hydrology and water resources (1978) at Institute of Hydrology, Madrid, Spain and at Institute of Hydraulic Research (1983), Porto Alegre, Brazil; MA in Political Sociology (1991), Federal University of Santa Catarina, Brazil, and $\mathrm{PhD}$ in Production Engineering (1998), Federal University of Santa Catarina, Brazil, and Post-doctorate (2005), Université du Québec à Montréal, Canada. http://lattes.cnpq.br/2909845332968569.
} 
this raises the solidity potential both the amount of data collected and its profundity.

It is important to point out that in the participantobservation protocol there is not only technical point of data collection, but there is also a demonstration of the need to insert the user in the product design process to be developed. This approach should be provided since product creation and idealization process, i.e., the user should have scored and analyzed the contributions from the beginning of development product. This union must be retained until the process of creation is completed.

As illustration it would be ask a user seated on a transport about the perception of comfort. People not involved in the scientific method would response: "good", "medium" or "bad." Just in case, if the perception is requested in details, the answers could be: "hemmed at the leg", "over soft" or "cause back pain" could be a pattern. Nevertheless, those ones who are immersed in the method can be able, when they are using the chair, to justify the positions adopted when seated; the supporting points that the body is sharing force with the object; which venous groups have been compressed causing dormancy; which muscle groups have suffered compression or stretch causing pain, etc. This process allows to understand, as widely as possible, not just what happens with humans when have interactions with the engineering product, but also during this interaction knows which motivations induce a person to act in a certain way, and what may be interesting to the design engineering area.

Following the above subject, in ergonomic can be realized a huge area for application of this methodology, being it inserted in production engineering and being responsible for most of the considerations made by designers in the beginning of the project. The addressed area - ergonomics - is the part of engineering that seeks the comfort development, safety and operational efficiency to the product end user. It is very important to highlight what Teiger [18] (2006) cited when she describes the experience in a production line as an ergonomics researcher following the participantobservation methodology:

Concerning the methodology of research, this immersion in its total explicitness, dives into an unknown environment to facilitate understanding instead of "participant-observation" adopted by some work psychologists and sociologists who observe the situations of work, usually incognito.

The participant-observation in question is given from the standpoint of the engineering that plans and structures ergonomic design, and the subjective data and impressions regarding the user. In this context, the exclusive user observation (even if the observer is properly acclimated in the observed space) opens gaps that only can be fulfilled when the observer is the user.

\section{Protocol application in production engineering research}

Upon completion of the review of the literature on the subject, and the presentation of the assertiveness that the method gives to engineering, an actual case of use of the method in production engineering research is presented briefly.

The Fig. 7 shows data extracted from a survey about the comfort in a means of a long-distance transport, when the passenger is seated in a chair. In this case, the research is conducted by a group of participant-observers carrying out the reading activity.

Comparing two observed moments during the course of action, and in this specific experiment, the average measured pressure variations were quite significant:

- On the glutei: from $37.10 \mathrm{mmHg}$ to 43.98 $\mathrm{mmHg}$;

- On the back: from17.19 $\mathrm{mmHg}$ to 18.21 $\mathrm{mmHg}$.

It was observed that from the moment " $A$ " (Fig. 1) to the moment "B" (Fig. 2), happened distinct shift in the position of the feet, which affects the legs and other body support. This caused an increase in back pressure and greatly increased pressure on the glutei, both as a consequence of reduced contact area with the seat (bringing back that pressure is the relationship between strength, in this case the weight, and the area to which relates the strength).

In this example, the participant-observer is supported by a device that records the pressure along the entire surface of the chair, besides of the cameras that record in video all sequence of postures take on the experiment. Even though, would lack the personal accounts of the user. It is not possible to determine in the literature which range of pressure can be called comfortable and from which values have been characterized discomfort. The account of the participant-observer reporting perceptions becomes crucial in understanding the situation studied. Only when the researcher informs to which sensations were 
submitted, and what motivation resulted certain posture, is starting to understand what the product analyzed rouse on a user.

Other computerized tools can be used, for example, virtual simulation software and reconstruction of human postures in three dimensions. Such images help greatly in understanding what is being studied. However, alone, as well as in the previous example, can not reveal the sensations that bodies support perceive, nor explain the motivations of human beings to act in a certain way when using the product. On the other hand, the images are of great value to the participant-observer so that it exactly covers the use of the product analyzed, being able to produce a more accurate reporting.

Naturally, a research that will use this methodology will be supported with several participant-observers, to be able to compare reports; the search for the extreme reports (similar to "maximum" and "minimum" reports) and what might be called "medium reporting" - information that on most of the researchers are related to the common perceptions. Also the diversity of biotypes of researchers is appropriate to expand the list of reports, and thus, provide more accurate information about the use of engineering product in question.

According to Caroll [19] (1996), this union between product developer and user is to be effective and provided correctly, it is essential that the user has complete knowledge of the situation to be experienced and the development progress of the proposed project, not just participate in random situations and examples that are followed by some vague statements of participants that even do not dominate the concept of the product to be developed. Thus, when run this way, the participantobservation protocol should be able to contribute not only with information in a specific situation, but with design requirements that may be adopted in creating later products or updates of it.

\section{Conclusion}

For the mentioned reasons, where the participantobservation is conducted through direct contact with the researcher with the phenomenon observed for getting information about the reality of social actors in own living environments, it is understood that effective participant-observation should be one in which the researcher seeks dominate the thought structure from the average public which would be the ideal observer, to propose a perform inside the experience and provide feedback as reliable as a guinea pig as if it were randomly chosen; and at the same time, as it is inserted into the experience, point toward to details that a population out of context to the survey should not highlight, by adding depth to the results achieved.

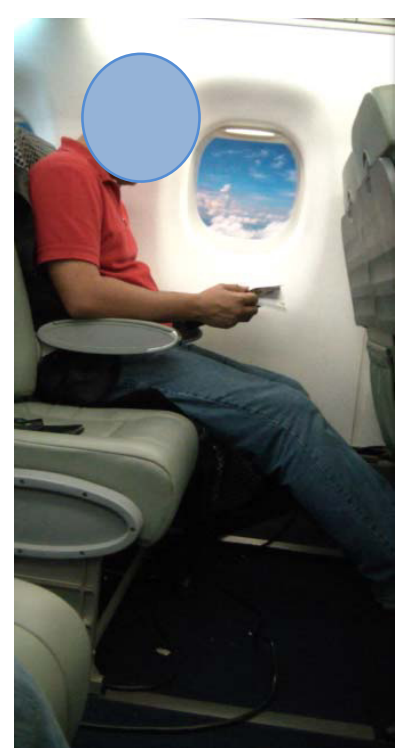

Fig. 1 - Moment “A”

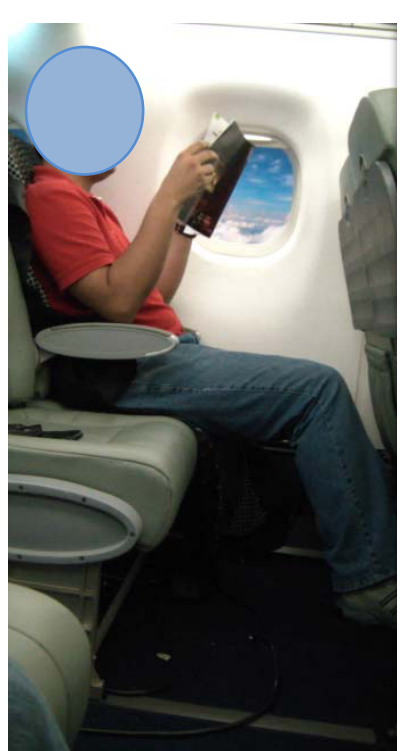

Fig. 2 - Moment "B" 


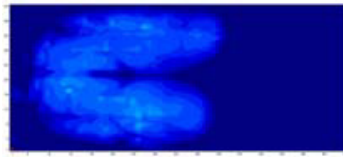

Fig. 3 -Glutei pressure "A"

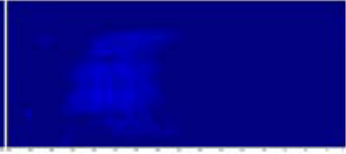

Fig. 4 - Back pressure "A"

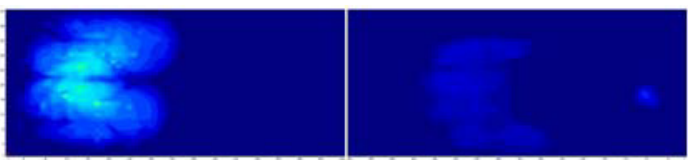

Fig. 5 - Glutei pressure "B" Fig. 6- Back pressure "B"

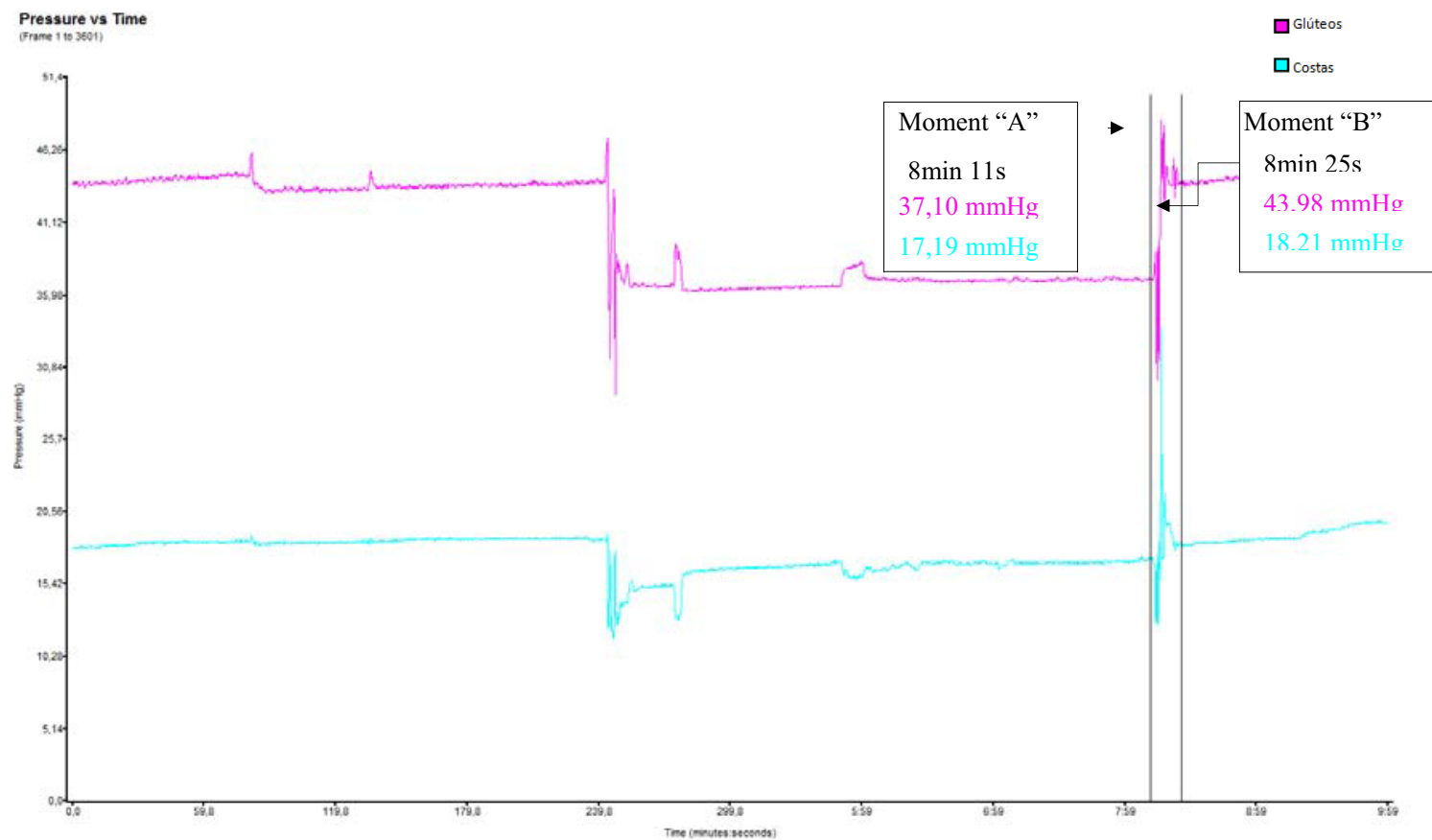

Fig. 7 -Pressure $(\mathrm{mmHg})$ Vs. Time $(\mathrm{min})$

Source: Empiric data raised by the researchers group. Not published.

Particularly to ergonomics, the participantobservation protocol adds immeasurable value, once goes beyond simple description and postural analysis - provides to the scientific research with the information relating to subjective feelings, sensations and perceptions, which are often not quantized, but are crucial for a correct understanding of evaluated context.

In conclusion, participant-observation protocol is not a mere and simple observation in order to provide complementary informations, but it must be understood as something that the researcher lives, takes part, become involved and also does it. Therefore, the participant-observer's experience is very useful in the industrial engineering field, more specifically within the products' design area, specially the interiors' design. By the time the sensations, perceptions and feelings of a human being using the product analyzed can be described with the participant-observation protocol, it is possible to forecast problems and reactions in the human-product relationship establishing solutions still in the design stage of a product's development.

\section{References}

[5] A. Cicourel, Teoria e método em pesquisa de campo, in: A.Z. Guimarães, Desvendando máscaras sociais, Rio de Janeiro, Livraria Francisco Alves, 1990, pp. 87-121.

[15]A.J. Alves-Mazzotti and F. Gewandsnajder, O planejamento de pesquisas qualitativas, in: $\mathrm{O}$ método nas ciências naturais e sociais, snd. ed., São Paulo: Pioneira Thompson Learning, 2002, cap. 7, pp. 147-178.

[9] A.L. Schmid, Introdução à metodologia, class nr. 7, Federal University od Paraná State (UFPR-Brazil), (s.d.).

[18]C. Teiger, et al, Quand les ergonomes sont sortis du laboratoire à propos du travail des femmes dans l'industrie électronique (1963 - 1973), Rétro-réflexion collective sur l'origine d'une dynamique de coopération entre action syndicale et recherche-formation-action. Pistes, v. 8, n. 2, 
Oct., 2006. Retrieved Nov. 11, 2009, from $<\mathrm{http}: / /$ www.pistes.uqam.ca/v8n2/articles/v8n2a4.htm>.

[17]D.J. Silva, Uma abordagem cognitiva ao planejamento estratégico do desenvolvimento sustentável, $\mathrm{PhD}$ thesis in production engineering, Federal University of Santa Catarina State (UFSC-Brazil), 1998.

[2] E.C. Lindernan, Social discovery, New York, 1924.

[10]E. Foster, Metodologia da pesquisa: pesquisa qualitativa. In: Seminário estudo de caso e observação participante. Universidade Federal do Amapá - UNIFAP, 1 1 ed. 2006.

[11]G.D. Garson, Participant observation and action research, Chass College of Humanities and Social Sciences, North Carolina State University, spring 2008. Retrieved Aug. 20, 2010, from http://faculty.chass.ncsu.edu/garson/PA765/ particip.htm.

[8] G.H. Mead, Mind, self, and society, Charles Morris, ed. Chicago, University of Chicago Press, 1934

[14] Guidelines for Ethical Conduct in Participant Observation. University of Toronto, Social Sciences and Humanities Research Ethics Board (SSH REB), Retrieved Nov. 11, 2009, from <http://www.research.utoronto.ca/ethics/pdf/ human/nonspecific/Participant\%20Observation\%20Guidelin es.pdf $>$.

[12]H.H.T.S. Martins, Metodologia qualitativa de pesquisa, Educação e Pesquisa, São Paulo, v.30, n.2, May/Aug., 2004. Retrieved Nov. 05, 2009, from $<\mathrm{http}$ //www.scielo.br/pdf/ep/v30n2/v30n2a07.pdf $>$.

[3] J.J. Hader and E.C., Lindeman, Dynamic Social Research, New York, 1933.

[19]J.M. Caroll, Encountering others: reciprocal openings in participatory design and user-centered design, in: HumanComputer Interaction, v.11/3, 1996, pp 285-290.

[7] M. Glancy, Participant observation in the recreation setting, Journal of Leisure Research, v. 18, n. 2, 1986, pp. 59-80. Retrieved Sep. 24, 2010, from http://www.duluth.umn.edu.

[4] N. Mack et al., Qualitative research methods: a data collector's field guide, U.S. Agency for International Development (USAID), Carolina do Norte (USA), 2005.

[13] Participant Observation. Retrieved Nov. 11, 2009, from $<$ www.sociology.org.uk/ mpoprint.pdf $>$.

[1] T.J. Bouchard, Field research methods: interviewing, questionnaires, participant observation, unobtrusive measures, in: Handbook of Industrial and Organizational Psychology, ed. M. D. Dunnette, Rand-McNally College Publishing Company, Chicago, 1976, pp. 363-414.

[6] T.M.F. Haguette, Metodologias qualitativas, in: Metodologias Qualitativas em Sociologia, Petrópolis, ed. Vozes, 1982, apud L.S.M. Costa, Observação participante. Retrieved Oct. 13, 2007, from <http://www.uff.br/ses/ arquivos/observacao $\% 20$ participante.pdf $>$.

[16]V.R.T. Ferreira and D.N. Mousquer, Observação em psicologia clínica, in: Revista de Psicologia, UnC, v. 2, n. 1, p. 54-61. Retrieved Nov 05, 2009, from $<$ http://www.nead.uncnet.br/2009/revistas/psicologia/3/36.pd f>. 